\title{
Peer Review: A Tool to Enhance the Quality of Academic Written Productions
}

\author{
Maria Fernanda Poveda de Brusa $^{1} \&$ Liliya Harutyunyan ${ }^{1,2}$ \\ ${ }^{1}$ School of Languages, Pontificia Universidad Católica del Ecuador, Quito, Ecuador \\ 2 de Octubre y Veintimilla, Quito, Ecuador \\ Correspondence: María Fernanda Poveda, School of Languages, Pontificia Universidad Católica del Ecuador, \\ Quito, Ecuador.
}

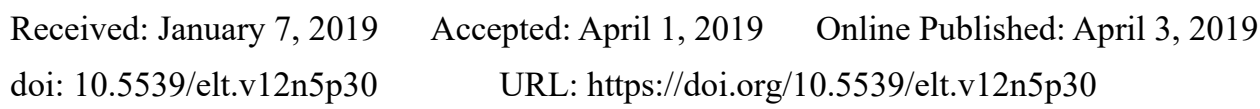

\begin{abstract}
Higher education focuses on promoting the training of autonomous, critical professionals who adapt to the ever-more demanding labor market. To achieve these objectives, it is necessary to rethink teaching practices in order to allow the student to be the main actor and modeler for their learning process.

Previous studies based on Vygotsky's sociocultural theory have shown that learning should be treated as a socio-cultural activity. Indeed, according to this approach, individual knowledge is firstly constructed at a social level. Peer review, for its part, is a learning tool based on the sociocultural approach. It allows students to achieve higher levels of autonomy and critical thinking.

This research's aim is, on the one hand, to analyze the effect of peer review on the quality of academic essays and, on the other, to examine the way in which linguistic and communicative competence in academic writing are affected. This experimental study was carried out with 68 level B1 + students (32 men and 36 women) in a private university in Ecuador during one academic year.

After the statistical analysis, it is concluded that peer review has a positive impact on academic writing. However, the impact is higher in the communicative competence than in the linguistic competence. This result is aligned with previous research, which shows that students tend to prioritize message over form.
\end{abstract}

Future research should investigate peer review's long-term impact upon students and their ability to transfer skills acquired in English class to other subjects, or even to professional contexts.

Keywords: higher education, peer review, academic writing, communicative and linguistic competence

\section{Introduction}

Vygotsky (1978) is the author who made significant contributions to the social constructivism approach. According to this approach, individuals build their knowledge at a social level and subsequently appropriate it individually. Social interaction serves to awaken cognitive processes and affects both cognitive and language development. That is, external activities are transformed into mental activities through processes of approximation and internalization. Extrapolating the foregoing to foreign language learning, the collaborative construction of knowledge is a source of L2 learning (Shehadeh, 2011). Therefore, students involved in collaborative processes build their knowledge more effectively than those who do so individually.

Peer review is a collaborative tool that fits within Vygotsky's socio-constructive model. For Falchicov (1995), peer review is a process in which individuals are evaluated among peers. The process may be facilitated by using rubrics previously created by others by the teachers, perhaps, or even elaborated by the group according to their needs. For Toppings (2009), peer review is a formative evaluation tool that allows students to evaluate their peers' performance, written products, and results in production quality improvement. In fact, through this process a better understanding and a broader perspective of the topic is achieved, and more meaningful learning and better-quality productions are therefore guaranteed. When using peer review in evaluation, both the student who reads, reviews and comments, and the student on the receiving end of said feedback, benefit. This happens because the student who is evaluated can take enormous advantage by engaging in meta-cognitive processes such as reflecting, justifying, accepting or critically rejecting the comments or suggestions of their peers (Liu \& 
Carless, 2006).

The afore mentioned fits perfectly with the swift of higher education aims. Indeed, higher education currently focuses, on the one hand, on training students to acquire specific skills for each profession; and on the other, on developing practices that place the student at the center of the learning process, and help them to achieve greater autonomy, enhance lifelong learning, and become critical thinkers. This new paradigm implies that methodologies and non-traditional evaluative processes, in which the student should take an active and interactive role, should be implemented (Lindblom-Ylänne, Pihlajamäki, \& Kotkas, 2006). To achieve this objective, the relationship between learning and its evaluation has been reviewed and new evaluation proposals have been developed, which include self-evaluation, peer evaluation, and group evaluation (Dochy, Segers, \& Sluijsmans, 1999).

Peer review is a tool widely used in the professional world and in courses such as Business, Technical Writing, Psychology, Social Sciences and Geography (Topping et al., 2000). But while the theory emphasizes that interaction and collaboration are essential for language acquisition, in practice, especially when it comes to evaluation in the context of an EFL class, the teacher becomes the only source of feedback. According to Choudhury (2005), for American students it is easier to interact and be actors in their learning process than students coming from different origins. L2 students carry their own culture's constructs and values with them. In many educational institutions in Ecuador, the teacher is still seen as an authority figure and the holder of knowledge. Consequently, students are limited to receiving knowledge imparted by the teacher. For that reason, placing students at the center and giving them autonomy in the learning process is counterintuitive to the norm.

This study incorporates the peer review tool in the core of the academic writing learning process. On the one hand, a clear improvement in the quality of academic essay productions has been observed, and on the other, peer review introduces students to a real and authentic communication activity. In addition, the learner who is involved in a peer review activity must change from a passive, receptive role to an active, negotiating role with $\mathrm{him} /$ herself and his/her peer. The tasks designed for students to provide each other with feedback during peer review will improve the quality of the classes' interaction and language use. Finally, collaborative learning allows students to develop critical thinking skills (Kaggan, 1992). According to Liu and Carless (2006), peer review is an end in itself: the person providing feedback develops critical reflection skills, learns to listen, evaluates using clear criteria, and provides good quality feedback. In addition, students who receive feedback also learn through meta-cognitive processes such as reflection and the capacity to justify their productions and accept or reject suggestions, all using their own argumentation.

Previous research concludes that written productions improve considerably when peer reviews are conducted by structured holistic and/or analytical evaluation rubrics. However, there are certain differences in the level at which improvements are most notable. Thus, for Storch (2005), significant changes occur at the level of grammatical accuracy and complexity. However, according to Lockhart and Ng. (1995), students have limited linguistic knowledge, so observations focus mainly on the content, organization and quality of ideas. A study conducted by Shehadeh (2011) concludes that there are no significant changes in terms of grammatical aspects or mechanics, but rather in relation to content areas, organization and vocabulary.

In addition, peer review introduces the student to a practice that is common in the professional world. In fact, as Topping (2009) points out, at some point in our professional life we can all expect to be peer evaluators and advisors. Therefore, peer review allows the development of skills and strategies that, though they are acquired in English, can be transferred according to students' needs to any other subject and in varied contexts.

However, Yang (2011), notes that previous studies highlight several points, of which the most relevant are, firstly, that it is likely that students will use this space to discuss issues not relevant to the task (Liou \& Peng, 2009); and secondly, that students tend to focus their corrections primarily on lexical aspects, leaving aside the text's organization and content (Cho Schunn, 2007).

As corollary, and since students do not arrive to class with evaluative skills, previous research suggests the need for explicit training in what it means to evaluate and be evaluated by their peers. Thus, Gielen \& De Wever (2015) carried out a study with first-year university students and concluded that previous, systematic instruction regarding the peer review process increased the possibility of achieving a positive impact. Other strategies to enhance the use of this tool include taking time to understand and analyze the rubrics (Miller, 2003). It is also possible to consider reviewing a case study with all students to understand the evaluation criteria (Sluijsmans \& Brand-Gruwel, 2002). In addition, it is highly recommended that rubrics be used to direct the peer review process and allow students to evaluate with greater criticism and objectivity.

However, we have not found any research on the incorporation of peer review in Ecuador or in the region, and in 
our opinion, carrying out this research in this specific context would be a great contribution. L2 students carry their cultural learnings with them. For this reason, it is possible that the results we obtain are different than those for other countries. This means that, while Peer Review fits perfectly in the US (a country where extensive studies have been carried out in this regard), the same will not necessarily occur in other contexts. In any case, this study's findings will be useful in obtaining points for discussion on how to implement and/or adapt these tools to the specificities of the context. On the other hand, as Shehadeh (2011) states, previous investigations have been carried out in ESL classes, and extending the research from ESL to EFL contexts can therefore grant new insights into peer review.

It should be emphasized that student participation in peer review develops a culture of reflection and critical analysis, not only regarding their work, but also regarding the learning outcomes and evaluation criteria intervening in the learning process. Many studies state that the writing process is, at present, not considered an individual task; rather, it is a task in which peer feedback should play an essential role (Liou \& Peng, 2009). Shared assessment positively contributes to students' performance and provides them with a new learning experience, through objectively judging work done by their peers - a task that will likewise be useful in their professional future. By incorporating the peer review tool into the writing process, students will be able to generate new ideas and perspectives by improving their writing skills (Lundstorm \& Baker, 2009).

\subsection{Research Objectives}

- Introduce the practice of peer review in academic writing classes, and assess whether or not it improves the quality of academic essays.

- Analyze which competences (linguistic or communicative) are mostly affected when introducing the practice of peer reviewing in academic writing classes.

\section{Method}

\subsection{Participants and Context}

This research was carried out with level B1 + students at a prestigious private university in Ecuador. We worked with 68 students (32 men and 36 women), whose mother tongue was Spanish. In this institution, students are enrolled in a variety of majors including, for example, Physical Therapy, Psychology, Civil Engineering, Tourism, Laws, Journalism, and Social Communication, among others. They have a 10-hour weekly load of English classes. It is a general English course and the communicative approach is used for the development of the four language skills.

In higher education institutions in Ecuador, English is a mandatory requirement for students to complete their major and graduate. In fact, Article 31 of the Regulations of the Academic Regime establishes that: "In third-level majors [that is, in the case of the students in this study] students must achieve proficiency in a foreign language, and with proficiency being understood as at least the level corresponding to B2 of the Common European Framework of Reference for Languages. However, obtaining English language proficiency is a challenge for a large majority of students.

\subsection{Experiment Procedure}

This study is of experimental nature. The sample was randomly divided into two groups: an experimental group and a control group. Based on previous experiments (Shehadeh, 2001), and in order to maintain consistency and validity in this research, the only variant that was introduced in the experimental group was the peer review procedure. Both the experimental and the control group thus had the same instructors, syllabus and content. The task for both groups was to write an argumentative essay based on documents previously studied and discussed in class.

In the control groups, during the academic writing process the students performed each writing process task (generation of ideas, organization of ideas, creation of the text, review, and editing) individually, and then handed this writing in to the teacher to receive their feedback. To move on the next stage, students corrected their drafts according to their teacher's observations. In the experimental groups, in contrast, students were reviewed by their peers. Their observations were written on the previously designed observation sheets. Then, before moving on to the next step of the writing process, they were given 15 minutes to discuss and explain the observations made.

The first phase of this study consisted of introducing students from both the experimental and control groups to the formalities and specificities of English academic writing. The writing process was broken down into the following stages: 
1). Pre-writing activities (brainstorming, listing, free writing, etc.)

2). Writing of essay thesis

3). Essay plan elaboration

4). Writing of introduction and conclusion

5). Drafting of essay paragraphs

6). Drafting the first version of the complete essay

7). Review and editing activities

8). Drafting of the final version

Worksheets were made for each of the previously mentioned stages, and in each section, the students had to write the corresponding part. Simultaneously, and following the suggestions from the literature, the experimental groups were introduced to the peer review methodology, gradually and prior to the start of their own reviews. This induction was done through readings, videos, practical exercises and case studies (Gielen \& De Wever, 2015; Miller, 2003; Sluijsmans, 1999).

Once the students were familiar with the peer review methodology, they chose their peer, and the activities were carried out following the schedule shown on the table below:

\begin{tabular}{ll}
\hline $\mathbf{N}^{\circ}$ week & Activity \\
\hline $1-2$ & Induction activities for the peer review method \\
3 & Pre-writing activities (brainstorming, listing, free writing, etc.) \\
4 & Peer-review: pre-writing activities \\
5 & Thesis writing \\
6 & Peer-review: thesis essay \\
7 & Development of the essay outline \\
8 & Peer review: essay outline \\
9 & Writing of introduction and conclusion \\
10 & Peer-review: introduction and conclusion \\
11 & Writing of body paragraphs \\
12 & Peer review: body paragraphs \\
13 & Writing the first version of the complete essay \\
14 & Peer-review: first version of the complete essay \\
15 & Drafting of the final version \\
16 & Handout of surveys \\
17 & Group reflections on the use of the peer review tool. \\
\hline
\end{tabular}

To carry out the peer review activities, the students used worksheets with reflection questions and rubrics that had been prepared in advance by the researchers (Miller, 2003). The students' evaluations did not have a numerical grade. The review consisted of at least two readings. In the first reading, reviewers had to focus on aspects of form, i.e., grammar, spelling and punctuation. Students were then asked to do a second, and if necessary, a third review focusing on more substantive aspects, which included content relevance, organization, cohesion, and a vocabulary usage in line with the essay's focus.

Once the readings were completed, and the corrections and comments had been made, the reviewers passed the section that they had corrected with their comments and evaluations to its writer, who read it, analyzed the pertinence of the corrections and comments, and then decided whether to accept or reject the suggestions before proceeding to the next stage.

\section{Data Collection and Analysis}

This investigation was a correlational-type study, since it associates variables through a predictable pattern for a group and population (Roberto Hernandez-Sampieri, 2008). 
The following variables were determined:

Independent variable $(X)$ : peer review.

Dependent variable (Y): quality of production and collaborative work.

The study lasted a year and the peer review methodology was applied with six different groups. Since the research was experimental, the sample was randomly divided into two groups. On the one hand was the experimental group, which was instructed in the academic writing learning process incorporating the peer review tool; and on the other was the control group, which was instructed in the usual way: that is, the teacher was in sole charge of providing feedback and evaluating the student.

The reviewer student did not give any numerical grades, but in both the experimental groups and the control groups, the first and second drafts were graded by the teachers. Quantitative data was thus obtained. To evaluate these productions, the scale proposed by Jacobs et al. (1981) was used. This scale has been widely used in various academic writing teaching contexts.

Jacobs proposes the evaluation of five aspects of writing, weighted as follows:

$\begin{array}{ll}\text { Content: } & 30 \text { points } \\ \text { Organization: } & 20 \text { points } \\ \text { Cohesion: } & 20 \text { points } \\ \text { Vocabulary: } & 20 \text { points } \\ \text { Language use: } & 25 \text { points } \\ \text { Language Mechanics: } & 25 \text { points }\end{array}$

\section{TOTAL \\ 120 points}

The comparison of the experimental and control groups was carried out through the "t-student, .05 level of significance" test.

\section{Results Obtained Through Statistical Analysis}

4.1 Question 1: Does Peer Review Improve the Quality of Students' Essays?

Table 1. Comparative sample of grades obtained in the first draft and in the final essay $(n=65)$

\begin{tabular}{llllll}
\hline & & Mean & Standard deviation & $t$ & Sig (bilateral) \\
\hline First draft & Control & 81.81 & 14.441 & -3.198 & .002 \\
& Experimental & 92.27 & 11.836 & -3.189 & .002 \\
Final essay & Control & 87.72 & 15.100 & -3.415 & .001 \\
& Experimental & 100.64 & 15.386 & -3.416 & .001 \\
\hline
\end{tabular}

As illustrated in table $\mathrm{N}^{\circ} 1$, when comparing the production of the control and experimental groups there is a marked improvement in the quality of production between the first essay and the final version. It is thus notable that in the first test, the control group obtains the following results: $\mathrm{M}=81.81, \mathrm{t}=-3.198$ and $\mathrm{Sig}=.002$; while the experimental group obtains $\mathrm{M}=92.27, \mathrm{t}=11.836$ and $\mathrm{Sig}=.002$.

The difference is still more significant in the final version of the essay. Here it can be noted that the control group result is $\mathrm{M}=87.72, \mathrm{t}=-3.415$ and $\mathrm{Sig}=.001$. and the experimental group obtains $\mathrm{M}=100.64, \mathrm{t}=-3.416$ and $\mathrm{Sig}=.001$.

4.2 Question 2: Does the Impact of Peer Review Vary Among the Different Domains of Writing (Content, Organization, Lexicon, etc.)? 
Table 2. Averages of the component scores on the first draft

\begin{tabular}{lllllll}
\hline & \multicolumn{5}{l}{ Control Group } & \multicolumn{4}{l}{ Experimental group } \\
\hline Component & Max score & $\mathrm{M}$ & SD & M & SD & $t$ \\
\hline Content & 30 & 20 & 3.52 & 22.61 & 3.47 & $-3.005^{* *}$ \\
Organization & 20 & 13.16 & 2.51 & 15.18 & 2.51 & $-3.244^{* *}$ \\
Cohesion & 20 & 13.25 & 2.74 & 15.55 & 2.26 & $-3.680^{* *}$ \\
Vocabulary & 20 & 13.75 & 3.04 & 15.39 & 2.46 & $-2.396^{*}$ \\
Language use & 25 & 16.66 & 4.99 & 17.15 & 3.81 & $-0.450^{*}$ \\
Punctuation & 10 & 5 & 2.04 & 6.38 & 1.9 & $-2.844^{* *}$ \\
\hline
\end{tabular}

$\mathrm{M}=$ arithmetic mean. $\mathrm{SD}=$ standard deviation. ${ }^{*} \mathrm{p}<.05 .{ }^{* *} \mathrm{p}<.01$.

Table 3. Averages of the component scores on the final draft

\begin{tabular}{|c|c|c|c|c|c|c|}
\hline & & \multicolumn{2}{|c|}{ Control group } & \multicolumn{3}{|c|}{ Experimental group } \\
\hline Component & Nota Max. & $\mathrm{M}$ & SD & $\mathrm{M}$ & SD & $t$ \\
\hline Content & 30 & 21.75 & 3.529 & 24.55 & 4 & $-2.984 * *$ \\
\hline Organization & 20 & 14.25 & 2.603 & 16.76 & 2.68 & $-3.824 * *$ \\
\hline Cohesion & 20 & 14.66 & 2.813 & 16.79 & 2.58 & $-3.184 * *$ \\
\hline Vocabulary & 20 & 15.00 & 3.005 & 16.75 & 3.49 & $-2.149 *$ \\
\hline Language use & 25 & 16.78 & 5.166 & 19.18 & 4.157 & $-2.067^{*}$ \\
\hline Punctuation & 10 & 5.47 & 2.079 & 7.12 & 1.933 & $-3.320 * *$ \\
\hline
\end{tabular}

$\mathrm{M}=$ arithmetic mean. $\mathrm{SD}=$ standard deviation. ${ }^{*} \mathrm{p}<.05 .{ }^{* *} \mathrm{p}<.01$.

The statistical analysis shows that throughout the writing process, the areas in which peer review has the highest impact are content, organization, cohesion and punctuation. In the areas of vocabulary and language use, the impact is lower.

4.3 Question 2: Does the Impact of Peer Review Vary Among the Different Domains of Writing (Content, Organization, Lexicon, etc.)?

Table 4. Averages of the component scores on the first draft on the experimental group

\begin{tabular}{|c|c|c|c|c|c|c|}
\hline \multirow[b]{2}{*}{ Component } & \multirow[b]{2}{*}{ Max score } & \multicolumn{2}{|c|}{ Control group } & \multicolumn{2}{|c|}{ Experimental group } & \multirow[b]{2}{*}{$t$} \\
\hline & & $\mathrm{M}$ & SD & $\mathrm{M}$ & SD & \\
\hline Content & 30 & 20 & 3.52 & 22.61 & 3.47 & $-3.005^{* *}$ \\
\hline Organization & 20 & 13.16 & 2.51 & 15.18 & 2.51 & $-3.244 * *$ \\
\hline Cohesion & 20 & 13.25 & 2.74 & 15.55 & 2.26 & $-3.680 * *$ \\
\hline Vocabulary & 20 & 13.75 & 3.04 & 15.39 & 2.46 & $-2.396^{*}$ \\
\hline Language use & 25 & 16.66 & 4.99 & 17.15 & 3.81 & $-0.450 *$ \\
\hline Punctuation & 10 & 5 & 2.04 & 6.38 & 1.9 & $-2.844 * *$ \\
\hline
\end{tabular}

$\mathrm{M}=$ arithmetic mean. $\mathrm{SD}=$ standard deviation. ${ }^{*} \mathrm{p}<.05 .{ }^{* *} \mathrm{p}<.01$.

The statistical analysis shows that throughout the writing process, the areas in which peer review has the highest impact are content, organization, cohesion and punctuation. In the areas of vocabulary and language use, the impact is lower. 


\section{Discussion}

Through the statistical analysis, it can be seen that in the context of this study, peer review has a positive impact on academic writing. This result aligns with previous studies, in which peer review also had a positive effect on the quality of written production (Crossman \& Kite, 2012; Shehadeh, 2011) and on the effectiveness of learning. In fact, these outcomes suggest that well-trained students are capable of giving feedback which is similar to, or even better than, that of the teacher (Topping, 2009).

We also noted that the better trained students are in relation to use of the peer review tool, the better the results obtained (in a comparison made between the first and the final drafts). Other researchers have likewise concluded that the best way to learn to interact in a foreign language is, precisely, by interacting (Choudhury, 2005).

It should be emphasized that these encouraging results are not due solely to the introduction of peer review in the writing process. According to the suggestions from the literature, the impact of the tool was enhanced with practical and prior instruction designed through scaffolding systems, so that students in the experimental groups could understand and apply the tool properly (Deni \& Rosnida, 2011; Gielen \& De Wever, 2015; Topping \& Smith, 2000). According to Guielen (2015), the aforementioned strategy has an impact not only on the final product, but also on the quality of feedback given and received by the students. Since the experimental group students worked on carrying out both the first and the second drafts in pairs, the positive results are evident even in the first draft.

It can be observed that the effect of using peer review during the academic writing process varies in each of its components. Thus, Skehan and Foster (2001) state that prioritizing message over form is common among language learners. Therefore, we note that in both the first and the second drafts, there is a highly significant impact in the areas of: content, organization, cohesion and punctuation. We noticed that, with the exception of the punctuation component, the remaining components are communicative.

Regarding content, the high impact could be due to the fact that when dealing with a controversial issue (fashion consumerism), teachers prepared a wide set of materials and activities that included a documentary, documents, press articles, discussions, and debates, so that students were immersed in the subject. However, when the discussion was in pairs, still more ideas emerged. The appropriate vocabulary use component has a significant impact on both drafts. We note a change regarding language use, however, since in the writing of the first draft there is no significant impact index, but in the second draft, the $\mathrm{P}>0.01$ indicates a positive impact.

Nonetheless, it can be seen that there is a generally less significant impact in terms of vocabulary adequacy and appropriate language use. This result could be considered somewhat surprising because, for example, in the study conducted by Storch (2005) who carried out a comparative study between a group of students who decided to write on an individual basis, and another group of students who decided to write collaboratively - the author concluded that the texts by students who worked in pairs were shorter but had greater complexity and grammatical accuracy; and consequently, the writing tasks performed in pairs were of better quality than those performed individually. However, this investigation corroborates the results obtained by Jegerski and Ponti (2014), who suggested that the process is quite lengthy in the areas of grammar and lexicon. Only following several months of university instruction was it possible to see slight results, and longer periods of instruction and practice were therefore required.

With an objective similar to that of this research, Storch (2005) investigated the process and product of collaborative writing, and students' views on it. She collected data from 23 adult ESL students completing a course at a large Australian university. Students were given the choice to write in pairs or individually. Eighteen students chose to work in pairs and five chose to work individually. The study compared texts produced by pairs with those produced by individual learners. The study also elicited learners' reflections and views on the CW experience. She also found that most students had positive outlooks on collaborative writing.

To make this discussion more comprehensive, we can also base our reflection on the insights of Sekehan (2011). He pointed out the issue of the complexity of the assigned task and the cognitive ability to process information, and indicated that humans have a limited capacity for processing information. EFL learners thus tend to prioritize message over form. When reviewing an argumentative essay, students become more focused on the content, which involves validating the essay thesis, evaluating the arguments and/or counterarguments, and perhaps even raising a controversial topic. Consequently, attention to the language itself is reduced (vocabulary adequacy, and the mechanics of spelling and punctuation). 


\section{Implications}

In general, this study generates results in line with those from previous investigations. Peer review is a tool that offers students clear benefits. However, in our context we noted that, while our students have already completed several years of higher education, they lacked the skills necessary to evaluate their peers. For that reason, they required a training period and constant monitoring by the teacher. Given the multiple benefits, it would be ideal for students to receive this training starting in the entry levels of university, or even during the pre-university courses.

\section{For Further Studies}

This study focused mainly on the products obtained following peer review. For future studies, the focus could be turned to the interactions within the pairs; that is, the social dynamics created in groups and their influence on cognitive processes (Van Den Berg et al, 2006). On the other hand, empirical evidence is lacking regarding peer review's effect over the long term. Further studies could therefore investigate whether students have been able to incorporate this practice into their broader academic life, or if the experience was strictly limited to the EFL class.

\section{References}

Andreu-Andrés, M. A. (2009). Los alumnos como evaluadores en el proceso de enseñanza-aprendizaje. Revista Iberoamericana de Educación. Retrieved from http://rieoei.org/expe/2877Andres.pdf

Bernabé Valero, G., \& Blasco Magraner, J. S. (2007). Evaluación por pares y autoevaluación en el aula universitaria: una visión desde el enfoque por competencias. Retrieved from http://web.ua.es/en/ice/jornadas-redes/documentos/2013-posters/335209.pdf

Byrmes, H. (2006). Languaging, agency and collaboration in advanced second language proficiency. In M. Swaim (Ed.), Advanced language learning the contribution of Halliday and Vygotsky (pp. 95-108). New York: Heydi Byrnes.

Cho, K., \& Schunn, C. D. (2007). Scaffolded writing and rewriting in the discipline: A web-based reciprocal peer review system. Computers \& Education, 48, 409-426. https://doi.org/10.1016/j.compedu.2005.02.004

Choudhury S. (2005). Interaction in Second Language Classrooms. BRAC University Journal, IINI, 77-82.

Consejo de Educación Superior. (2017). Reglamento de Régimen Académico (Codificación). Gaceta Oficial del Consejo de Educación Superior (CES). Retrieved from http://www.ces.gob.ec/index.php?option=com_phocadownload\&view=category\&download=524:reglament o-de-regimen-academico\&id=12:reglamentos-expedidos-por-el-ces\&Itemid=266

Crossman, J., \& Stacey, K. (2012). Facilitating improved writing among students through directed peer review. Active Learning in Higher Education, 13(3), 219-229. https://doi.org/10.1177/1469787412452980

Falchikov, N. (1995). Peer feedback marking: Developing peer assessment. Innovations in Education and Training International, 32, 175-187. https://doi.org/10.1080/1355800950320212

Gielen, M., \& De Wever, B. (2015). Structuring peer assessment: Comparing the impact of the degree of structure on peer feedback content. Computers in Human Behavior, 52, 315-325. https://doi.org/10.1016/j. chb.2015.06.019

Hammersley, M., \& Traianou, A. (2012). Ethics and Educational Research, British Educational Research Association. Retrieved from https:/www.bera.ac.uk/wp-content/uploads/2014/03/Ethics-and-EducationalResearch.pdf?noredirect $=1$

Jamsen, K. (2015). Making Peer Review Work. University of Wisconsin. Retrieved from https://writing.wisc.edu/ wac/node/78

Kiefer, K. (2015). Teaching Guide: Using Student Peer Review. University of Colorado. Retrieved from http://writing.colostate.edu/guides/teaching/peer/index.cfm

Lindblom, S., Pihlajamaki, S., \& Kotkas, T. (2006). Self, peer and teacher assessment of student essays. Active Learning in Higher Education, 7, 51-62. https://doi.org/10.1177/1469787406061148

Liou, H., \& Peng, Z. (2009). Training effects on computer-mediated peer review. System, 37, 514-525. https://doi.org/10.1016/j.system.2009.01.005

Liu, N., \& Carless, D. (2006). Peer feedback: The learning element of peer assessment, Teaching in Higher Education, 11(3), 279-90. https://doi.org/10.1080/13562510600680582 
Lockhart, C., \& Ng, P. (1995). Analyzing talk in ESL peer response groups: Stances, functions and content. Language Learning, 45, 605-655. https://doi.org/10.1111/j.1467-1770.1995.tb00456.x

Lundstrom, K., \& Baker, W. (2009). To give is better than to receive; the benefits of peer review to reviewers' own writing. Journal of Second Language Writing, 18, 30-43. https://doi.org/10.1016/j.jslw.2008.06.002

McMillan, J. H., \& Schumacher, S. (2010). Investigación Educativa (5th ed.). Madrid: Pearson.

Miller, P. (2003). The Effect of Scoring Criteria Specificity on Peer and Self-assessment. Assessment \& Evaluation in Higher Education, 28(4), 383-394. https://doi.org/10.1080/0260293032000066218

Pylväinen, H., DeCourcy, D., Hutton, L., Silver, N., \& Chamberlin, J. (2011). Using Peer Review to Improve Student Writing. University of Michigan.

Rieber, L.J. (2006). Using peer review to improve students' writing in business courses. Journal of Education for Business, 81(6), 322-6. https://doi.org/10.1016/j.sbspro.2015.07.543

Sachs, J., \& Parsell, M. (2013). Peer Review of Learning and Teaching in Higher Education: International Perspectives. New York, NY: Springer.

Shehadeh, A. (2011). Effects and student perception of collaborative writing in L2. Journal of second language writing in L2, 20(4), 286-305. https://doi.org/10.1016/j.jslw.2011.05.010

Storch, N. (2005). Collaborative writing; Product, process, and students' reflections. Journal of Second Language Writing, 14(3), 153-173. https://doi.org/10.1016/j.jslw.2005.05.002

Swaim, M., \& Lapkin, S. (2006). "Oh I get it now" from production to comprehension in second language learning, In D. M. Brinton, \& O. Kagan (Eds.), Heritage Language Acquisition: A new field emerging, Mahwah. NJ: Lawrance Erlbaum.

Skehan, P., \& Foster, P. (2001). Cognition and tasks. In P. Robinson (Ed.), Cognition and Second Language Instruction. Cambridge, MA: Cambridge University Press. https://doi.org/10.1017/CBO9781139524780. 009

Sluijsman, D., Brand-Gruwel, S., \& van Merriënboer, J. (2002). Peer-assessment Training in Teacher Education: Effects on Performance and Perceptions. Assessment \& Evaluation in Higher Education, 27(5), 443-454. https://doi.org/10.1080/0260293022000009311

Topping, K. J. (2009). Peer assessment. Theory into Practice, 48(1), 20-27. https://doi.org/10.1080/004058408 02577569

Topping, K. J., Smith, E. F., \& Swanson, I. (2000). Formative peer assessment in academic writing between post-graduate students. Assessment and evaluation in Higher Education, 25(2), 149-169. https://doi.org/ $10.1080 / 713611428$

Vera-Cazorla, M. J. (2014). La evaluación formativa por pares en línea como apoyo para la enseñanza de la expresión escrita persuasiva. Universidad de Las Palmas de Gran Canaria. Retrieved from http://www.um.es/ead/red/43/vera.pdf

Vygotsky, L. S. (1978). Mind and society. Boston, MA: Harvard University Press.

Yahg, Y. (2011). A reciprocal peer review system to support college students' writing. British Journal of Educational Technology, 42(4), 687-700. https://doi.org/10.1111/j.1467-8535.2010.01059.x

\section{Appendix A}

\section{WRITING ASSESSMENT SCORING RUBRIC}

STUDENT'S NAME:

Date:

\section{A. Relevance and adequacy of content}

30-27__ EXCELLENT TO VERY GOOD: relevant and adequate answer to the task set.

26-22 _ GOOD TO AVERAGE: For the most part task is successfully completed, though there may be some gaps or redundant information.

$21-17$

FAIR TO POOR: Answer of limited relevance to the task set. Possibly major gaps in treatment of 
topic and/or pointless repetition.

16-13

VERY POOR: The answer bears almost no relation to the task set. Totally inadequate answer

\section{B. Compositional organization}

20-18_ EXCELLENT TO VERY GOOD: Overall shape and internal pattern clear. Organizational skill adequately controlled.

$17-14$ GOOD TO AVERAGE: Some organizational skills in evidence, but not adequately controlled.

$13-10$ development. FAIR TO POOR: Very little organization of content, lacking of logical sequencing and

9-7 VERY POOR: No apparent organization of content.

\section{Cohesion}

20-18 EXCELLENT TO VERY GOOD: Satisfactory use of cohesion resulting in effective communication.

17-14___ GOOD TO AVERAGE: For the most part satisfactory cohesion although occasional deficiencies may mean that certain parts of the communication are not always effective.

13-10 _ FAIR TO POOR: Unsatisfactory cohesion may cause difficulty in comprehension of most of the intended communication.

9-7__ VERY POOR: Cohesion almost totally absent. Writing so fragmentary that comprehension of the intended communication is virtually impossible.

\section{Adequacy of vocabulary for purpose}

20-18___ EXCELLENT TO VERY GOOD: Almost no inadequacies in vocabulary for the task. Only rare inappropriacies and/or circumlocution.

17-14___ GOOD TO AVERAGE: Some inadequacies in vocabulary for the task. Perhaps some lexical inappropriacies and/or circumlocution.

13-10 ___ FAIR TO POOR: Frequent inadequacies in vocabulary for the task. Perhaps frequent lexical inappropriacies and/or repetition.

9-7___ VERY POOR: Vocabulary inadequate even for the most basic parts of the intended communication.

\section{E. Language use}

$25-22$ inaccuracies.

EXCELLENT TO VERY GOOD: effective complex constructions. Almost no grammatical

21-18

GOOD TO AVERAGE: Effective but simple constructions. Some grammatical inaccuracies.

$17-11$ FAIR TO POOR: Major problems in simple/complex constructions. Frequent grammatical inaccuracies.

$10-5$

VERY POOR: Virtually no mastery of sentence construction rules. Almost all grammatical patterns inaccurate.

\section{F. Mechanics}

10-9___ EXCELLENT TO VERY GOOD: Few errors of spelling, punctuation, capitalization, paragraphing.

8-6__ GOOD TO AVERAGE: Occasional errors of spelling, punctuation, capitalization, paragraphing.

5-3 _ FAIR TO POOR: Frequent errors of spelling, punctuation, capitalization, paragraphing.

1-2__ VERY POOR: No mastery of conventions, dominated by errors of spelling, punctuation, capitalization, paragraphing.

Adapted from Jacobs et al's (1981) scoring profile and TEEP attribute writing scales (Weir, 1990)

\section{Copyrights}

Copyright for this article is retained by the author(s), with first publication rights granted to the journal.

This is an open-access article distributed under the terms and conditions of the Creative Commons Attribution license (http://creativecommons.org/licenses/by/4.0/). 